\title{
Dietary generalism accelerates arrival and persistence of coral-reef fishes in their novel ranges under climate change
}

\author{
Cristián J. Monaco, ${ }^{1,2}$ (D) | Corey J. A. Bradshaw ${ }^{3}$ (D) | David J. Booth ${ }^{4}$ (D) | \\ Bronwyn M. Gillanders ${ }^{1}$ (D) | David S. Schoeman ${ }^{5,6}$ (D) | Ivan Nagelkerken ${ }^{1}$ (D)
}

${ }^{1}$ Southern Seas Ecology Laboratories, School of Biological Sciences and The Environment Institute, The University of Adelaide, Adelaide, SA, Australia

${ }^{2}$ IFREMER, IRD, ILM, UPF, UMR

Ecosystèmes Insulaires Océaniens, Taravao, Tahiti, Polynésie française

${ }^{3}$ Global Ecology, College of Science and Engineering, Flinders University, Adelaide, SA, Australia

${ }^{4}$ School of Life Sciences, University of Technology Sydney, Sydney, NSW, Australia

${ }^{5}$ Global-Change Ecology Research Group, School of Science and Engineering, University of the Sunshine Coast, Sunshine Coast, QId, Australia

${ }^{6}$ Centre for African Conservation Ecology, Department of Zoology, Nelson Mandela University, Port Elizabeth, South Africa

\section{Correspondence}

Cristián J. Monaco and Ivan Nagelkerken, Southern Seas Ecology Laboratories, School of Biological Sciences and The Environment Institute, DX 650 418, The University of Adelaide, Adelaide, SA 5005, Australia. Email: cristian.monaco@ifremer.fr; ivan.nagelkerken@adelaide.edu.au

\section{Funding information}

Australian Research Council, Grant/Award Number: DP170101722

\begin{abstract}
Climate change is redistributing marine and terrestrial species globally. Life-history traits mediate the ability of species to cope with novel environmental conditions, and can be used to gauge the potential redistribution of taxa facing the challenges of a changing climate. However, it is unclear whether the same traits are important across different stages of range shifts (arrival, population increase, persistence). To test which life-history traits most mediate the process of range extension, we used a 16-year dataset of 35 range-extending coral-reef fish species and quantified the importance of various traits on the arrival time (earliness) and degree of persistence (prevalence and patchiness) at higher latitudes. We show that traits predisposing species to shift their range more rapidly (large body size, broad latitudinal range, long dispersal duration) did not drive the early stages of redistribution. Instead, we found that as diet breadth increased, the initial arrival and establishment (prevalence and patchiness) of climate migrant species in temperate locations occurred earlier. While the initial incursion of range-shifting species depends on traits associated with dispersal potential, subsequent establishment hinges more on a species' ability to exploit novel food resources locally. These results highlight that generalist species that can best adapt to novel food sources might be most successful in a future ocean.
\end{abstract}

\section{KEYWORDS}

climate change, coral reefs, functional traits, generalist, marine fishes, range shifts, temperate ecosystems

\section{1 | INTRODUCTION}

Climate change is altering the distribution of marine and terrestrial species globally, thus emerging as a major concern for conservation planners and resource managers increasingly challenged with uncertain future conditions (Pecl et al., 2017). The a priori expectation is that many species should be able to track the displacement of their preferred temperature envelope to maintain optimal physiological performance (Parmesan \& Yohe, 2003; Poloczanska et al., 2013; Tingley, Monahan, Beissinger, \& Moritz, 2009). However, the high variability in rate and direction of species' range shifts calls for improved mechanistic understanding of the underlying processes driving them (La Sorte \& Jetz, 2012; Pinsky, Worm, Fogarty, Sarmiento, \& Levin, 2013; Sunday et al., 2015).

While climate change-related range shifts are mainly driven by environmental forcing (Poloczanska et al., 2007), species' lifehistory traits can mediate the process, offering a mechanistic link between the ability to cope with novel environmental conditions and the potential to redistribute (Bradshaw et al., 2014; Ehrlich, 1986). Studies of climate change-related range shifts have consequently sought to identify the main traits that can serve as general proxies of invasion potential and improve our ability 
to predict redistribution events of animals and plants in both aquatic and terrestrial environments (Foden et al., 2013; Sunday et al., 2015). Studies of taxa in different types of communities have identified overarching traits that can predict dynamics across systems, and other traits that only explain responses idiosyncratically depending on the specific environmental conditions (Angert et al., 2011). For instance, a species' native latitudinal range is a commonly measured trait to predict shift potential because it aligns with a species' ability to operate under a wide range of environmental conditions (Lodge, 1993; Sunday et al., 2015). On the other hand, other traits like body size can be context-dependent. For example, if range extension depends more on a species' reproductive potential and propagule pressure, larger species should be better colonizers than smaller species (e.g. Feary et al., 2014; Roy, Jablonski, \& Valentine, 2002). However, if the distribution shift hinders a species' ability to grow and reproduce swiftly, smaller, $r$-selected species can demonstrate the most lability in redistribution (e.g. Perry, Low, Ellis, \& Reynolds, 2005). Therefore, taking advantage of the insights that species' traits can offer requires careful consideration of the ecological conditions operating in each context (Sunday et al., 2015).

Climate-mediated range shifts can be broadly divided into three sequential stages: arrival, population growth, and persistence (Bates et al., 2014; Estrada, Morales-Castilla, Caplat, \& Early, 2016). Because species experience fundamentally different challenges during each of these stages, we should a priori expect shifts in the importance of different traits that confer success during each stage. This implies that the ecological contexts might also vary as a function of the stage-specific importance of alternative life-history traits (Estrada et al., 2016). For example, while a species' ability to disperse between suitable habitat patches is an essential component of success for the arrival stage, dispersal capacity might not provide any advantages during the growth or persistence stages when an individual's ability to avoid novel predators or consume novel food items is likely to be more important. However, most of the evidence connecting species traits to their potential for redistribution is derived either from historical analyses of species that have effectively reached a stage of persistence in their new habitats (e.g. McLean, Mouillot, \& Auber, 2018; Pinsky et al., 2013) or modelling studies that project establishment probability (e.g. Anderson, 2013). Only by examining in real time which traits facilitate initial arrival of range-shifting species, and then subsequent persistence in novel habitats, can we test these hypotheses directly (Fogarty, Burrows, Pecl, Robinson, \& Poloczanska, 2017; Roy et al., 2002).

Range shifts driven by climate change are particularly rapid in marine ecosystems, where the body temperature of ectotherms typically tracks that of the surrounding sea water, and behavioural thermoregulation is generally not an option (Pinsky, Eikeset, McCauley, Payne, \& Sunday, 2019; Sunday, Bates, \& Dulvy, 2012). Owing to climate change-induced intensification of southward ocean currents (Ridgway, 2007), and above-average rates of warming along the south-eastern coast of Australia (Hobday \& Pecl, 2014), there is ample evidence now of tropical and subtropical fish species increasingly shifting poleward in this region (Booth, Figueira, Gregson, Brown, \& Beretta, 2007; Figueira \& Booth, 2010; Fowler, Parkinson, $\&$ Booth, 2017). While most of these species have yet to establish reproductive populations in this still-temperate region, empirical data and projections suggest that permanent relocations will occur in the next decade (Fowler et al., 2017), making this an ideal system to investigate relationships between life-history traits of tropical species and their time of arrival and persistence in a temperate region.

We used a 16-year survey dataset to test general hypotheses derived from trait-based studies that have compared range-shifting and non-shifting species. Our analysis magnifies previous analyses (Booth et al., 2007; Feary et al., 2014) that identified traits separating vagrant from non-vagrant tropical-reef fishes in south-eastern Australia. Most notably, these studies suggested that (a) latitudinal distribution range, (b) pelagic larval duration (PLD), and (c) species' maximum body size favour arrival (Booth et al., 2007; Feary et al., 2014). While these traits relate directly to a species' ability to expand its distributional limits, it is uncertain whether these same traits play a role in the arrival and persistence stages of range-shifting species. Because a species' dietary characteristics can also contribute to their invasion potential (Kingsbury, Gillanders, Booth, \& Nagelkerken, 2019; Sunday et al., 2015), we tested the hypotheses that trophic level and diet breadth-both previously hypothesized proxies for ecological generalism (Lodge, 1993; Rooney, McCann, \& Moore, 2008; Sunday et al., 2015) -drive earlier arrival (i.e. earliness) and higher persistence (i.e. higher prevalence and lower patchiness) across these range-shifting species.

\section{2 | MATERIALS AND METHODS}

\section{1 | Fish occurrence}

We used time series of occurrence data for coral-reef fishes (i.e. presence/absence) in south-eastern Australia collected at two temperate sites located beyond the target species' historical poleward range edges: Cabbage Tree Bay, Sydney $\left(33^{\circ} 48^{\prime} 00^{\prime \prime} \mathrm{S}\right.$, $151^{\circ} 17^{\prime} 50^{\prime \prime} \mathrm{E}$ ) and Bar Beach, Merimbula (36 $53^{\prime} 45^{\prime \prime} \mathrm{S}, 1^{\circ} 9^{\circ} 55^{\prime} 26^{\prime \prime} \mathrm{E}$; Booth et al., 2007). Both sites are characterized by shallow $(<5 \mathrm{~m}$ depth) rocky reefs featuring patches of kelp, sessile filter feeders, and bare rock.

Surveys were done by snorkel, using the roaming underwater visual-census method (Beck, Feary, Figueira, \& Booth, 2014), covering areas of $\sim 240 \mathrm{~m}^{2}$ at each site. The surveys were done at least monthly between 2003 and 2018 (Booth et al., 2007; Fowler et al., 2017), and more regularly during the summer and early autumn (January-April). We worked with the first two trimesters of the year because the East Australia Current is strongest during this period, and consequently, the recruitment of tropical fishes to this temperate region is highest. Few individuals survive the winter through to the third trimester (Booth et al., 2007; Fowler et al., 2017). We grouped these data by year to calculate 
establishment metrics and examine the influence of life-history traits.

Our analyses assumed that the detection probability was similar among species, as strong deviations from this expectation could bias the results. We tested this assumption by comparing the detection probability of species that were present using the R package unmarked (Fiske \& Chandler, 2011). We worked with species positively identified at both sites and for each year because both factors can affect the occurrence of these vagrant fishes. While this constraint meant that only a subset of all the species could be considered in this analysis, our estimates suggest that the detection probabilities were similar among species (overlapping 95\% confidence intervals; Figure S1).

\section{2 | Establishment metrics}

We determined earliness, prevalence, and patchiness for each species and site using the occurrence time series. We defined earliness as $\left(1+N Y_{t}-y_{1}\right) N Y_{t}^{-1}$, where $y_{1}$ is the first year of detection (ordinal value), and $N Y_{t}$ is the total number of survey years (i.e. 16). Prevalence is $N Y_{d} / N Y_{t}$, where $N Y_{d}$ is the number of years with positive detection. We calculated patchiness as $\sum N Y_{n d} N G^{-1} N Y_{t}^{-1}$, where $N Y_{\text {nd }}$ is the number of years of no-detection (i.e. gap widths), and NG the number of non-detection gaps across the period of the study. All three metrics were thus expressed as proportions, with high values of earliness indicating early detection of the species during the study period, and low and high values of prevalence and patchiness reflecting high persistence. We emphasize that these indices represent different phenomena: prevalence indicates the overall occupancy of a site, whereas patchiness describes the temporal heterogeneity of that occupancy. The overall invasive potential of range-shifting species can be described by these three responses. The a priori expectation is that they are correlated in a manner consistent with invasiveness potential-that is, earliness and persistence are high for highly invasive species. However, departures from this expectation are also conceivable given high stochasticity associated with larval dispersal (Siegel et al., 2008). To illustrate these possible scenarios, consider four hypothetical species exhibiting high, low, and two intermediate invasion potentials, respectively (Figure S2). With high earliness and persistence (i.e. high prevalence, low patchiness), species 1 and 2 align along the plots' diagonal, whereas intermediate invasiveness, due to changes in prevalence and patchiness, manifests as departures from this line.

\section{3 | Models of establishment metrics}

\subsection{1 | Species traits}

We tested the effects of maximum body size (i.e. maximum total length, in $\mathrm{cm}$ ), geographical extent (i.e. latitudinal range, in degrees latitude), PLD (i.e. mean PLD, in days), trophic level, and diet breadth on the three establishment metrics.
For body size and geographical extent, we used data from FishBase (Froese \& Pauly, 2019), complemented with information from Feary et al. (2014). We note that geographical extent can be confounded with the historical distribution of species; however, a correlation between these species' latitudinal ranges and their southern distribution limit suggested otherwise $(r=.31, p=.08)$. Pelagic larval duration, also used by Feary et al. (2014), was provided by one of the authors of the aforementioned study (O. J. Luiz, personal communication). We calculated trophic level using data describing food items for each target species and their prey obtained from FishBase (Froese \& Pauly, 2019), following Borstein, Fordyce, O'Meara, Wainwright, and McGee (2016). We used the R package rfishbase to access the raw diet data (FishBase, Food II category), which included 17 possible diet items encompassing algae, detritus, benthic and pelagic invertebrates, and fishes (Table S2). The diet of fishes can vary across their life stages; however, we treated the information available in FishBase as representative of each species. We chose this because (a) in most instances, the life stages are not indicated in FishBase, and because (b) the relative diet breath of adults and juveniles of each species are positively correlated. For every species in our list, we estimated the percent contribution of prey items by 100 random permutations of the ranking of prey items, using the R package dietr (Borstein, 2019). We used the estimated contribution of the prey items and their trophic levels to calculate the trophic level of our target species (Borstein et al., 2016). We calculated (scaled; ordinated) diet breadths using an ordination approach that estimates the proportion of multivariate space occupied by the food items of each target species, relative to those of an extreme generalist. We calculated pairwise dissimilarity matrices among the fishes' food items using Jaccard-transformed distances, and applied it to a principal coordinates analysis to place each individual food item in a multivariate ordination space. We then placed the fishes on the centroid of this space to determine proportional diet breath. We did these calculations using the R package ordiBreath (Fordyce, Nice, Hamm, \& Forister, 2016). To avoid misusing the information available in the global database FishBase, we carefully assessed the quality of the data retrieved for the few species we considered. We worked with scaled predictor values (z-scores) to allow direct comparisons of their effect sizes. To tackle the potential issue of high-leverage points, we ran two additional versions of the models: (a) transforming the species traits by adding the lowest value to each predictor and $\log _{10}$-transforming the data and (b) excluding the species Abudefduf vaigiensis because it appeared to be an outlier. This, however, did not alter the main results (see Section 3). To test for multicollinearity between predictors, we calculated Pearson's correlation coefficients.

\subsection{2 | Models}

To test hypotheses about the influence of species traits on the earliness and persistence (prevalence and patchiness), we fitted betaregression models using the $\mathrm{R}$ package gamlss (general additive models 
for location, scale, and shape; Stasinopoulos \& Rigby, 2007). We chose GAMLSSs because they can describe response variables constrained between zero and one (i.e. beta-distributed error distributions: BE), which we modelled as: $y \sim \mathrm{BE}(\mu, \sigma)$, where $\mu$ and $\sigma$ represent the distribution parameter's mean (i.e. location) and standard deviation (i.e. shape), respectively. The latter parameter allowed modelling variability in the shape of the distribution explained by taxonomic family, thus controlling partially for possible phylogenetic relationships among species (Felsenstein, 1985). While other dedicated computational tools exist for modelling binomial-distributed data while correcting for phylogenetic relationships, no methods are available for data with beta- and zero-inflated beta-error distributions.

We computed several competing models that included all combinations of species traits considered, site, and the effect of taxonomic family on the standard deviation of the data. We chose the top-ranked model based on Akaike's information criterion (AIC) using the function stepAIC in the gamlss package, and determined model performance based on Cox-Snell's pseudo $R^{2}$ (Stasinopoulos $\&$ Rigby, 2007). To evaluate the adequacy of the top-ranked models, we examined the residual Q-Q and worm plots visually (Buuren \& Fredriks, 2001). Worm plots are detrended Q-Q plots that provide information of the model performance at specific ranges of the predictors. Adequate models are indicated if the points are contained within the upper and lower worm-plot boundaries, and along the diagonal line in the $\mathrm{Q}-\mathrm{Q}$ plots. To test whether the models effectively accounted for any structure introduced by the phylogenetic relationships, we examined plots between the squared difference between pairs of residuals and their phylogenetic distance. We extracted phylogeny data from the National Center for Biotechnology Information using the R package taxize (Chamberlain \& Szocs, 2013).

\section{3 | RESULTS}

\section{1 | Occurrence patterns and establishment metrics}

From a total of 71 tropical species recorded at least once in Sydney or Merimbula during the study period (2003-2018), 60 species (84.5\%) belonged to the four most representative taxonomic families (Acanthuridae, Chaetodontidae, Labridae, and Pomacentridae), and we retained these for the subsequent analyses. We further reduced the number of species within these four families to those for which the complete set of life-history traits we considered were available ( $n=35$ species; Table S1).

Range-shifting species differed in their patterns of arrival at temperate sites. While some occurred consistently at both sites (e.g. A. vaigiensis), others were documented only once (e.g. Sydney: Chaetodon lunula; Merimbula: Acanthurus lineatus), or were not recorded at all at a site (e.g. Zebrasoma velifer at Merimbula). We also observed some species that first arrived during the study period, and were then consistently recorded for the remainder of the time series (e.g. Sydney: Ctenochaetus striatus, Figure S3; Merimbula: Thalassoma lunare, Figure S4). Several species were recorded for the first time in the years $2010-2011: 26 \%$ and $20 \%$ of the species documented at Sydney and Merimbula, respectively (Figures S3 and S4).

The calculated establishment metrics of earliness and persistence (i.e. prevalence and patchiness) further illustrated the variability in species' patterns of arrival and provided the necessary data to test the influence of life-history traits (see Section 3.2). The establishment metrics were correlated in a manner consistent with the expected species' invasion potential (Figure S5). We found positive associations between earliness and prevalence at both sites (Spearman's rank-order correlation; Sydney: $\rho=0.747, p<.001$; Merimbula: $\rho=0.948, p<.001)$. In contrast, earliness was negatively correlated with patchiness in Sydney $(\rho=-0.754, p<.001)$ and Merimbula ( $\rho=-0.950, p<.001)$, and prevalence was negatively correlated with patchiness in Sydney $(\rho=-0.991, p<.001)$ and Merimbula ( $\rho=-0.990, p<.001$; Figure S5).

Despite an apparent grouping of the establishment metrics according to taxonomic family (Figures S5 and S6), logistic regression models evaluated with likelihood-ratio tests revealed no mean effects of family for either Sydney (earliness: $\chi^{2}=0.529, d f=3, p=.912$; prevalence: $\chi^{2}=0.232, d f=3, p=.972$; patchiness: $\chi^{2}=0.083, d f=3$, $p=.993$ ) or Merimbula (earliness: $\chi^{2}=6.307, d f=3, p=.097$; prevalence: $\chi^{2}=2.354, d f=3, p=.502$; patchiness: $\chi^{2}=2.909, d f=3$, $p=.405)$. In contrast, the variance in the establishment metrics attributed to taxonomic family improved model performance (see Section 3.2).

\subsection{Influence of life-history traits on establishment}

Using beta-regression models to test the hypothesized influence of species' life-history traits on the establishment metrics (Figures S7S9), we found that the top-ranked models explained $31.8 \%$ $(w A I C=0.491), 53.3 \%(w A I C=0.709)$, and $37.1 \%($ wAIC $=0.834)$ of the variance for earliness, prevalence, and patchiness, respectively (Table 1). These models adequately described the underlying structure of the data (Figure S10), and accounted for the possible influence of phylogenetic relationships (Figure S11). The correlation analyses to test for multicollinearity revealed that only maximum body size and PLD were strongly correlated ( $r=.76$; Figure S12). However, because these variables did not emerge as the dominant predictors in the top-ranked models (see below), we did not exclude them from the analysis. Furthermore, the information-theoretic AIC model-ranking approach differently penalizes multiple-parameter models containing strongly correlated fixed effects. The predictors diet breadth and trophic level were also positively associated, although weakly ( $r=.39$; Figure S12).

Overall, we found that site and diet breadth were the strongest contributors to explaining variance in all three of the establishment metrics (Figure 1; Table 1). The top-ranked models indicated that earliness and prevalence were greater at the warmer site Sydney than the colder site Merimbula (logit-link coefficients; earliness: $\mu=1.097, S E=0.335$; prevalence: $\mu=1.355, S E=0.287$ ), while 


\begin{tabular}{|c|c|c|c|c|c|c|}
\hline Model & LL & $d f$ & AIC & $\Delta \mathrm{AIC}$ & wAIC & $R^{2}$ \\
\hline \multicolumn{7}{|l|}{ Earliness } \\
\hline $\mathrm{S}+\mathrm{DB}+\mathrm{TrL}+\mathrm{LR}+\mathrm{F}$ & 89.8 & 9 & -162 & 0.00 & 0.491 & .318 \\
\hline $\mathrm{S}+\mathrm{DB}+\mathrm{TrL}+\mathrm{LR}$ & 86.5 & 6 & -161 & 0.74 & 0.339 & .249 \\
\hline $\mathrm{S}+\mathrm{DB}+\mathrm{TrL}+\mathrm{ToL}+\mathrm{LR}+\mathrm{PLD}+\mathrm{F}$ & 90.7 & 11 & -159 & 2.34 & 0.153 & .334 \\
\hline$S+F$ & 82.8 & 6 & -154 & 8.03 & 0.009 & .166 \\
\hline $\operatorname{TrL}+\mathrm{F}$ & 81.9 & 6 & -152 & 9.93 & 0.003 & .143 \\
\hline$D B+F$ & 81.8 & 6 & -152 & 10.1 & 0.003 & .141 \\
\hline ToL + F & 80.5 & 6 & -149 & 12.6 & 0.001 & .110 \\
\hline Null & 76.5 & 2 & -149 & 12.8 & 0.001 & - \\
\hline$P L D+F$ & 78.8 & 6 & -146 & 16.1 & $<0.001$ & .065 \\
\hline \multicolumn{7}{|l|}{ Prevalence } \\
\hline $\mathrm{S}+\mathrm{DB}+\mathrm{TrL}+\mathrm{ToL}+\mathrm{LR}+\mathrm{F}$ & 82.8 & 10 & -146 & 0 & 0.709 & .533 \\
\hline $\mathrm{S}+\mathrm{DB}+\mathrm{TrL}+\mathrm{ToL}+\mathrm{LR}+\mathrm{PLD}+\mathrm{F}$ & 82.9 & 11 & -144 & 1.79 & 0.29 & .535 \\
\hline $\mathrm{S}+\mathrm{DB}+\mathrm{TrL}+\mathrm{ToL}+\mathrm{LR}$ & 73.5 & 7 & -133 & 12.6 & 0.001 & .391 \\
\hline$D B+F$ & 66.9 & 6 & -122 & 23.7 & $<0.001$ & .266 \\
\hline$S+F$ & 64.8 & 6 & -118 & 27.9 & $<0.001$ & .220 \\
\hline $\operatorname{TrL}+\mathrm{F}$ & 62.9 & 6 & -114 & 31.8 & $<0.001$ & .176 \\
\hline ToL + F & 61.5 & 6 & -111 & 34.6 & $<0.001$ & .143 \\
\hline Null & 56.1 & 2 & -108 & 37.3 & $<0.001$ & - \\
\hline$P L D+F$ & 59.8 & 6 & -108 & 38.1 & $<0.001$ & .099 \\
\hline \multicolumn{7}{|l|}{ Patchiness } \\
\hline$S+D B+L R$ & 59.9 & 5 & -110 & 0.00 & 0.834 & .371 \\
\hline $\mathrm{S}+\mathrm{DB}+\mathrm{LR}+\mathrm{F}$ & 61.2 & 8 & -106 & 3.46 & 0.148 & .394 \\
\hline $\mathrm{S}+\mathrm{DB}+\mathrm{TrL}+\mathrm{ToL}+\mathrm{LR}+\mathrm{PLD}+\mathrm{F}$ & 62.1 & 11 & -102 & 7.66 & 0.018 & .409 \\
\hline$S+F$ & 53.2 & 6 & -95 & 15.3 & $<0.001$ & .239 \\
\hline $\mathrm{DB}+\mathrm{F}$ & 49.5 & 6 & -87 & 22.8 & $<0.001$ & .154 \\
\hline Null & 43.7 & 2 & -83 & 26.5 & $<0.001$ & - \\
\hline $\operatorname{TrL}+\mathrm{F}$ & 47.4 & 6 & -83 & 27.0 & $<0.001$ & .101 \\
\hline $\mathrm{ToL}+\mathrm{F}$ & 46.1 & 6 & -80 & 29.6 & $<0.001$ & .067 \\
\hline PLD + F & 45.2 & 6 & -78 & 31.4 & $<0.001$ & .043 \\
\hline
\end{tabular}

TABLE 1 Beta-regression model rankings. Information-theoretic rankings of candidate beta-regression models for earliness, prevalence, and patchiness. For each establishment metric, models are arranged according to Akaike's information criterion (AIC). Log-likelihood (LL), degrees of freedom (df), difference in AIC between the top-ranked and current model ( $\triangle \mathrm{AIC}$ ), AIC weight (wAIC), and Cox-Snell's 'pseudo' coefficient of determination $\left(R^{2}\right)$ are also provided

Note: Model variables influencing the mean response $(\mu)$ S, site; DB, diet breadth; TrL, trophic level; ToL, maximum total length; LR, latitudinal range; PLD, pelagic larval duration. The continuous variables were scaled (z-scores). Model variables influencing the standard deviation $(\sigma)$ : F, taxonomic family.

patchiness was greater at Merimbula $(\mu=-1.487, S E=0.316)$. Diet breadth had a positive effect on earliness ( $\mu=0.443, S E=0.193)$ and prevalence ( $\mu=0.803, S E=0.178)$, and a negative effect on patchiness $(\mu=-0.671, S E=0.168)$. We further illustrate the isolated effect of diet breadth with partial-effects plots (Figure 2).

Our models detected a weaker influence of other life-history traits, whose contributions varied between establishment metrics (Figure 1; Table 1). The top-ranked models included a negative effect of species' latitudinal range on earliness $(\mu=-0.252, S E=0.176)$ and prevalence $(\mu=-0.414, S E=0.176)$, and a positive effect on patchiness $(\mu=0.292, S E=0.155)$. We found that higher trophic level increased both earliness ( $\mu=0.345, S E=0.173$ ) and prevalence $(\mu=0.265, S E=0.169)$, and that prevalence was also partly explained by the species maximum body length ( $\mu=-0.303, S E=0.208)$. We found no support for the role of PLD on either of the establishment metrics (Figure 1; Table 1). The relative support (wAIC) for all models that examined the effects of life-history traits independently was as low as that of the null models (Table 1). Computing the models using $\log _{10}$-transformed predictors or excluding the high-influence species (A. vaigiensis) did not alter the main conclusion, that diet breadth was the most influential trait (Figure S13), although the strength of this effect was reduced for the earliness model that excluded $A$. vaigiensis (Figure S13b).

The top-ranked models for earliness and prevalence included effects of taxonomic family on the variance (Figure 1; Table 1). Overall, Pomacentridae (damselfishes) had the highest variance in both metrics, and Acanthuridae (surgeonfishes, tangs, unicornfishes) had the lowest (Figure 1; Figure S6). In contrast, including taxonomic family in the patchiness models did not improve predictions (Figure 1; Table 1). 
(a)

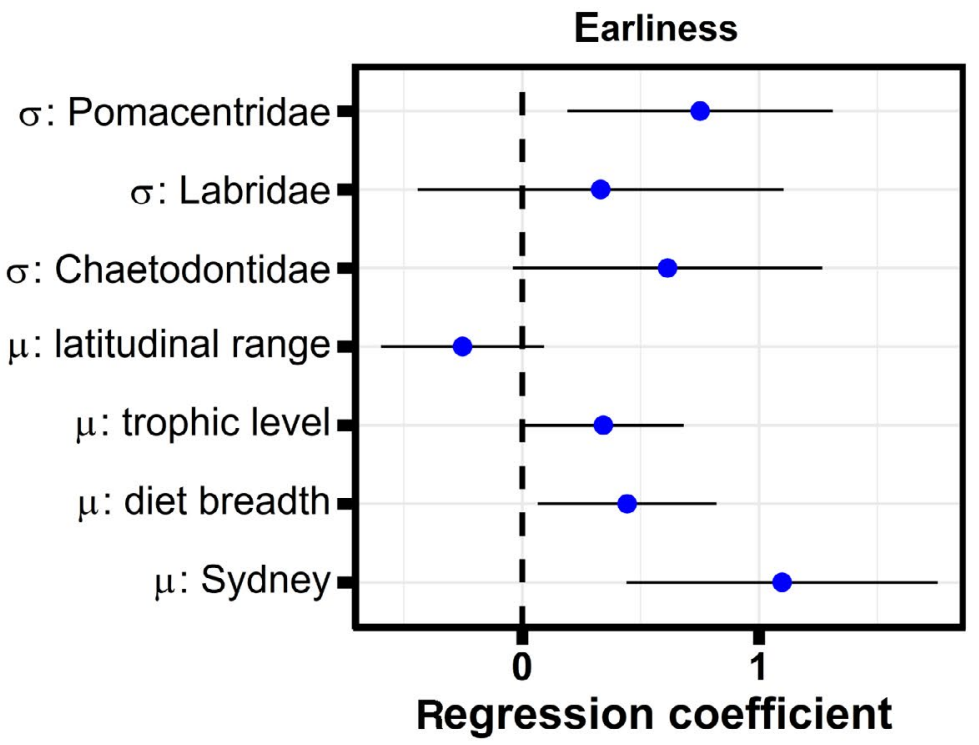

(b)

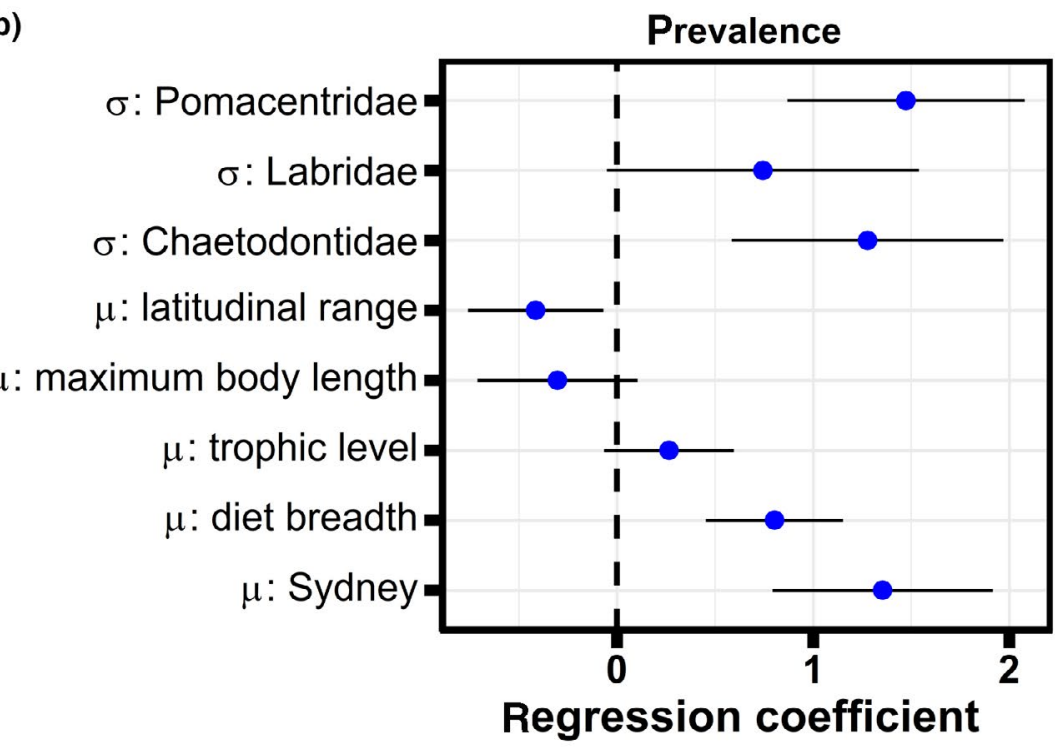

(c)

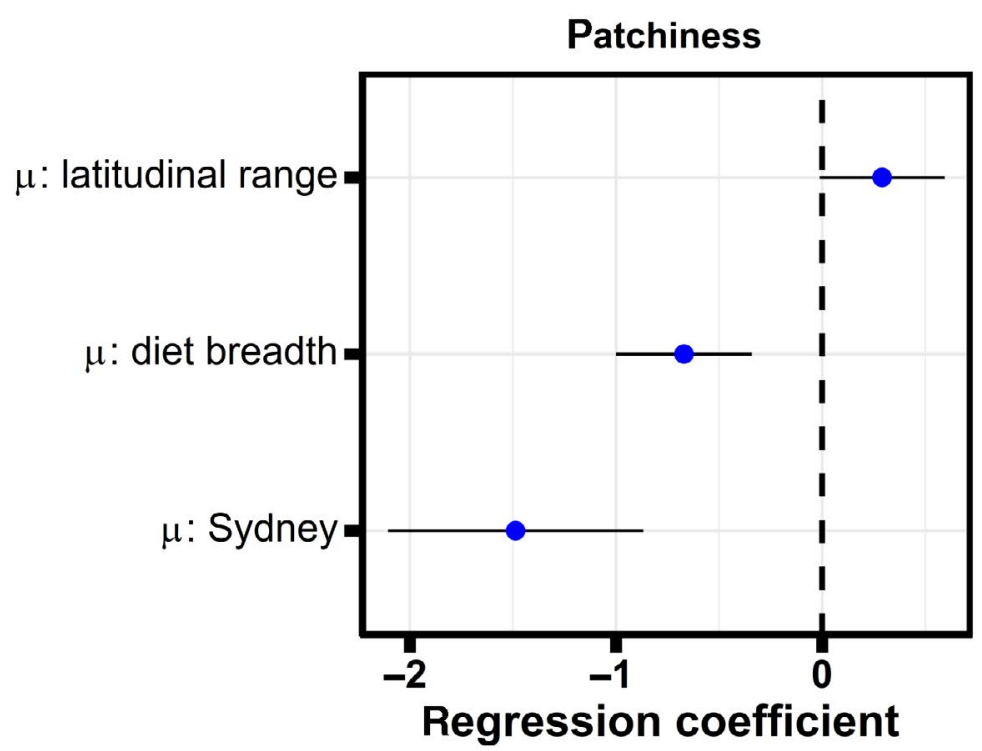

FIGURE 1 Effect plots derived from the top-ranked general additive models for location, scale, and shape (GAMLSS) describing (a) earliness (year of arrival, scaled and reversed), (b) prevalence (proportion of surveys with occurrences), and (c) patchiness (mean gap width across the period of the study, scaled) of tropical species recorded at Sydney and Merimbula. Regression coefficients (logit scale) are depicted by blue points, with standard errors illustrated by horizontal lines. The parameters $\mu$ and $\sigma$ represent the mean effects of relevant covariates and the standard deviation attributed to each family, respectively. The estimated $\sigma$ are specific to the estimate of the reference family (i.e. Acanthuridae). The estimated $\mu$ : Sydney values are specific to the reference site (i.e. Merimbula) [Colour figure can be viewed at wileyonlinelibrary. com] 


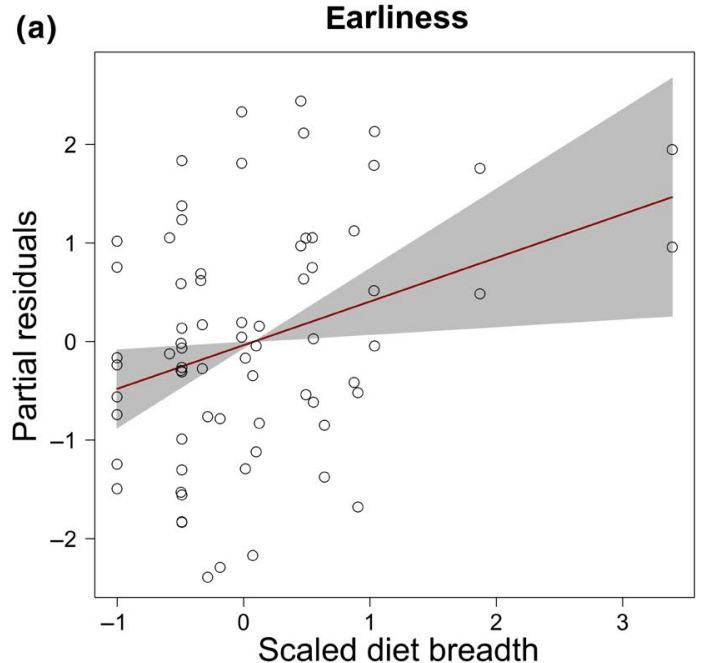

(b) Prevalence

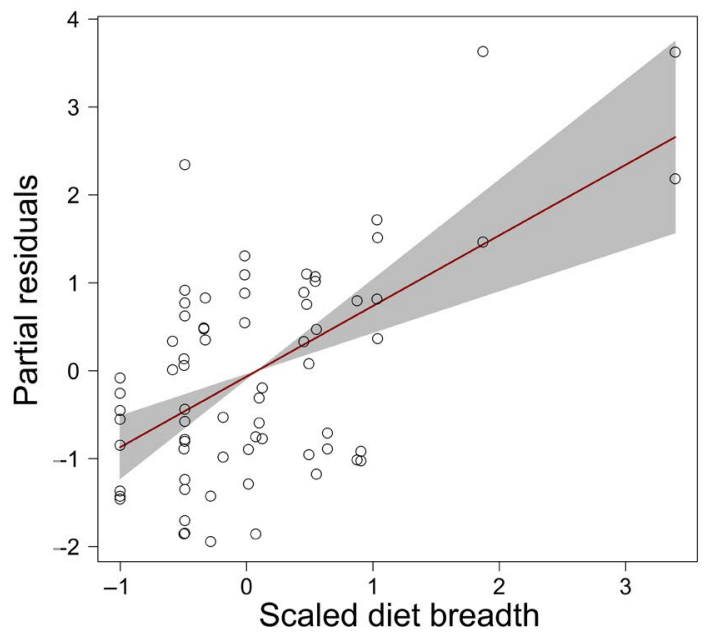

(c)

Patchiness

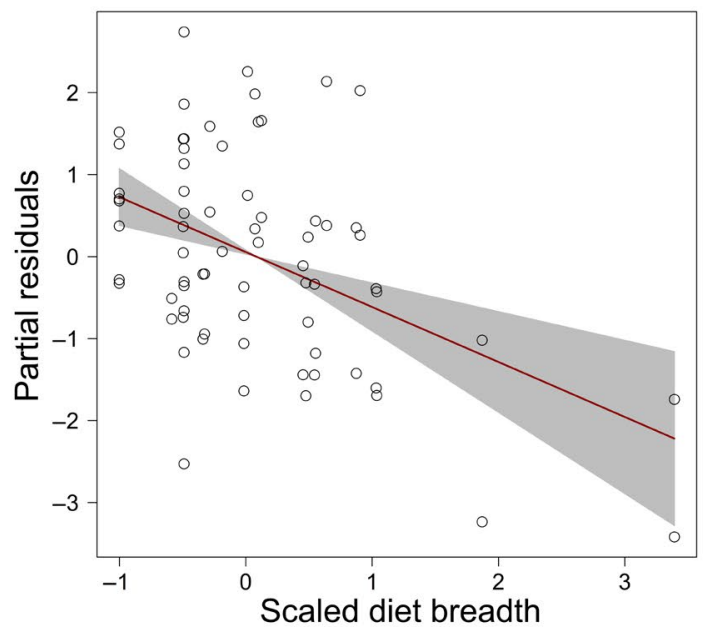

FIGURE 2 Partial residuals for the effect of top-ranked lifehistory trait (i.e. scaled diet breadth, z-scores) on the (a) earliness (year of arrival, scaled and reversed), (b) prevalence (proportion of surveys with occurrences), and (c) patchiness (mean gap width across the period of the study, scaled) of tropical species documented at Sydney and Merimbula. The lines show fitted linear models, and the shaded areas represent standard errors on the slope coefficient $(\mu)$ of diet breadth [Colour figure can be viewed at wileyonlinelibrary.com]

\section{4 | DISCUSSION}

We show that the importance of life-history traits on the invasion potential of tropical coral reef fishes changes across the stages of climate change-facilitated range shifts. While the potential for a species to settle in temperate habitats has been previously associated with large body size, extended PLD, and a wide native range size (Booth et al., 2007; Feary et al., 2014), our models indicate that these traits are poor predictors of a species' time of arrival and establishment. Instead, we reveal that the chief contributor to earliness and persistence of range-extending fish species is diet breadth (i.e. dietary generalism).

By definition, generalist species can cope with wider ranges of environmental conditions than specialists (Gilchrist, 1995), so our finding that the potential for establishment into new habitats is greater for the more flexible species is not surprising. However, the condition of generalism can be ascribed to a hypervolume of traits, each of which can differ in importance depending on a particular set of biotic and abiotic circumstances (Betzholtz, Pettersson, Ryrholm, \& Franzén, 2013; Gilchrist, 1995; Kingsbury et al., 2019; Matis, Donelson, Bush, Fox, \& Booth, 2018). Our models identified which traits and ecological mechanisms (i.e. wide diet breadth) best predicts the early stages of establishment of tropical-reef fishes expanding towards temperate latitudes of south-eastern Australia. Our models also ruled out the role of a species' latitudinal range, another broadly cited proxy for ecological generalism (Lodge, 1993; Sunday et al., 2015), but that nevertheless can explain the potential for range shifts in these fishes (Feary et al., 2014). Although our top-ranked models included latitudinal range as a predictor for prevalence and patchiness, its relative effect was minor compared to that of the main contributors: site and diet breadth. Moreover, the effect of latitudinal range was opposite to what we had initially expected, providing little support for its relevance during these stages of the range-extension process. Thus, the relative contribution of this driver appears to erode with the stages of range extension for these tropical-reef fishes.

The tropical species currently settling along temperate shores of south-eastern Australia have been categorized more or less dichotomously as either facultative- or non-coral feeders (Feary et al., 2014), but within these classifications, the extent of their diet flexibility can vary substantially. This phenomenon was demonstrated by the method we used to quantify diet breadth (Fordyce et al., 2016), which yielded a continuous predictor with adequate resolution to capture dietary variability across species, and its relationship with the establishment metrics. As hypothesized, we found that the species that arrived earlier and showed higher prevalence (and lower patchiness) had wider diet breadths. The general agreement between the responses of earliness, prevalence, and patchiness is evidence for the overarching importance of diet on the invasive potential of tropical vagrants at two distinct stages of the range shift (i.e. arrival and persistence). Our results support the conclusions of a global meta-analysis that compared multiple traits of native and non-native aquatic species and highlighted omnivory as a critical attribute of successful 
range shifters (McKnight, García-Berthou, Srean, \& Rius, 2017). Additionally, McKnight et al. (2017) found a positive relationship between invasiveness and trophic level, which our top-ranked models for earliness and prevalence supported, albeit weakly. There was little variability in the trophic level among the species we modelled because they are mostly secondary consumers and herbivores, which could partially explain why the effect was weak. Trophic level was weakly correlated with diet breadth $(\rho=0.39$, $\mathrm{Cl}=0.07-0.64)$, a link that has been previously proposed as the underlying reason for the apparent effect of trophic level (Rooney et al., 2008; Sunday et al., 2015). Thus, for the mid-trophic guild we examined here, the decisive role of diet breadth does not appear confounded by trophic level.

Two mechanisms likely explain the comparative advantage of diet-generalists over specialists. First, access to the appropriate food is of course necessary for organisms to meet energetic demands and survive post-settlement (Pratchett, Berumen, Marnane, Eagle, \& Pratchett, 2008; Riechert, 1991). Second, a wide diet breadth can limit competition for food and promote coexistence (Kingsbury et al., 2019; Schoener, 1974). Kingsbury et al. (2019) demonstrated that several of the tropical vagrants we examined can modify their trophic niche at the leading edge of their range extension, effectively reducing the overlap with local temperate species. A direct benefit of group foraging made possible by dietary generalism exists for the omnivorous tropical vagrant Abudeduf vaigiensis, which grows faster in mixed compared to mono-specific shoals (Smith, Fox, Booth, \& Donelson, 2018), presumably because it learns to forage for local food items. An indirect benefit is the possible reduction in the risk of predation (Godin, 1986), which here arises from the ability to forage indiscriminately in single- or multi-species aggregations. Altogether, these empirical observations and our results provide a strong case for the determinant role of diet breadth on the colonization success of these tropical vagrants, and its value as a predictor of ongoing species redistributions.

Although we focused on the role of life-history traits rather than environmental forcings in determining redistribution success, spatial variability in the establishment metrics can also reflect the aggregate effect of different environmental conditions. Particularly for this system, variation in ocean currents ultimately dictates the rates at which larvae from northern locations are delivered to temperate sites (Booth, Bond, \& Macreadie, 2011). Our models indicated that earliness and persistence were higher at warmer site Sydney than colder site Merimbula, in agreement with their relative distance to tropical source populations. Because coastal hydrodynamics can interact with fishes' life-history traits to determine settlement success (Wong-Ala et al., 2018), we expected that the attributes modifying propagule pressure (i.e. maximum body length, PLD) mediated the variability in establishment metrics, but this was not the case. Such effects can in fact be weakened or negated by the eddy dynamics and offshore advection that characterize the hydrodynamics at Sydney, and especially at the more poleward site, Merimbula (Condie, Mansbridge, \& Cahill, 2011). Thus, the overriding influence of coastal oceanography (Siegel et al., 2008) likely explains the low support we found for the effects of body size and PLD on time of arrival and persistence.

Our establishment metrics were partially intercorrelated. The (expected) correlations among these response variables are interesting because they suggest that there is a continuum in the invasive potential of these species overall, which persists through the early stages of establishment (arrival and persistence). However, more interesting are the many deviations from the perfect correlation, which highlight (a) that each establishment metric encapsulates different ecological processes and (b) the highly stochastic nature of this range shift. For example, Pomacentrus brachialis arrived early in Sydney relative to most other species, but it had a low prevalence and intermediate patchiness. This species' single occurrence was likely the result of an event not predictable with limited data. However, we can attribute the increases in recruitment during the 2010-2011 La Niña event to intensified southward advection arising from natural climatic oscillations (Pearce, Hutchins, Hoschke, \& Fearns, 2016; Wilson et al., 2018) rather than anthropogenic climate change per se. We also maintain that our proxies for persistence, prevalence, and patchiness were complementary, because patchiness provided a measure of the temporal heterogeneity in prevalence. That patchiness was generally low, irrespective of prevalence, indicates that the southward incursions of these species were occurring consistently on average. This is additional evidence that range shift induced by climate change is affecting an assemblage of tropical-reef fishes (Booth et al., 2007; Fowler et al., 2017), and not just a few species.

Beyond the traits we examined, the future establishment of breeding populations of tropical fishes in Sydney and Merimbula will depend on the interplay between local sea-surface temperatures (especially in winter) and the thermal sensitivities of and interactions among species (Figueira, Curley, \& Booth, 2019; Monaco \& Helmuth, 2011). Winter mortalities currently outnumber recruitment, so the survey data we used do not yet indicate true relocations, but first intrusions that will likely result in an eventual poleward shift in ranges over the coming decades (Fowler et al., 2017). Such early observations of species shifting distributions are nevertheless necessary to describe more completely the processes driving range shifts of some species, but not others (Fogarty et al., 2017). Our study therefore provides the first quantitative evidence demonstrating the variable role of life-history traits across the different stages of climate-driven shifts in species ranges-a notoriously challenging objective given the highly variable trajectories that species can follow (La Sorte \& Jetz, 2012). The complex ecological mechanisms involved in range expansions (Pinsky et al., 2013; Sunday et al., 2015) will therefore require continued enhancement of data and models to improve predictive capacity across the full transition from arrival to persistence.

\section{5 | CONCLUSIONS}

Life-history traits are strong predictors of species' ability to follow the pace of climate change. However, we demonstrate that the contribution of specific traits can vary depending on the ecological processes 
driving their dynamics. While dispersal of tropical fishes is aided by traits associated with high propagule pressure, establishment hinges on their ability to consume local food resources via a generalist diet.

\section{ACKNOWLEDGEMENTS}

This project was supported by an Australian Research Council Discovery grant (DP170101722) to I.N., D.J.B., D.S.S. and B.M.G. Thanks to $\mathrm{H}$ Beck, G Beretta and A Fowler for assisting D.J.B. during field surveys. $O$. Luiz helped retrieve the pelagic larval duration data. We are grateful to D Smith for constructive comments on the manuscript.

\section{AUTHOR CONTRIBUTION}

All authors contributed to the original concept. C.J.M. and C.J.A.B. chose the analyses. C.J.M. did the analyses and led the writing. All authors contributed to revision of the manuscript.

\section{DATA AVAILABILITY STATEMENT}

All data and code are available in the GitHub repository github.com/ cristianmonaco/Diet-generalism-favours-range-expansion.

\section{ORCID}

Cristián J. Monaco iD https://orcid.org/0000-0003-4057-5290 Corey J. A. Bradshaw iD https://orcid.org/0000-0002-5328-7741 David J. Booth (iD https://orcid.org/0000-0002-8256-1412 Bronwyn M. Gillanders (iD https://orcid.org/0000-0002-7680-2240 David S. Schoeman (iD https://orcid.org/0000-0003-1258-0885 Ivan Nagelkerken (iD https://orcid.org/0000-0003-4499-3940

\section{REFERENCES}

Anderson, R. P. (2013). A framework for using niche models to estimate impacts of climate change on species distributions. Annals of the New York Academy of Sciences, 1297(1), 8-28. https://doi.org/10.1111/ nyas. 12264

Angert, A. L., Crozier, L. G., Rissler, L. J., Gilman, S. E., Tewksbury, J. J., \& Chunco, A. J. (2011). Do species' traits predict recent shifts at expanding range edges? Ecology Letters, 14(7), 677-689. https://doi. org/10.1111/j.1461-0248.2011.01620.x

Bates, A. E., Pecl, G. T., Frusher, S., Hobday, A. J., Wernberg, T., Smale, D. A., ... Watson, R. A. (2014). Defining and observing stages of climate-mediated range shifts in marine systems. Global Environmental Change, 26, 27-38. https://doi.org/10.1016/j.gloenvcha.2014.03.009

Beck, H. J., Feary, D. A., Figueira, W. F., \& Booth, D. J. (2014). Assessing range shifts of tropical reef fishes: A comparison of belt transect and roaming underwater visual census methods. Bulletin of Marine Science, 90(2), 705-721. https://doi.org/10.5343/bms.2013.1055

Betzholtz, P.-E., Pettersson, L. B., Ryrholm, N., \& Franzén, M. (2013). With that diet, you will go far: Trait-based analysis reveals a link between rapid range expansion and a nitrogen-favoured diet. Proceedings of the Royal Society B: Biological Sciences, 280(1750), 20122305. https:// doi.org/10.1098/rspb.2012.2305

Booth, D. J., Bond, N., \& Macreadie, P. (2011). Detecting range shifts among Australian fishes in response to climate change. Marine and Freshwater Research, 62(9), 1027-1042. https://doi.org/10.1071/MF10270

Booth, D. J., Figueira, W. F., Gregson, M. A., Brown, L., \& Beretta, G. (2007) Occurrence of tropical fishes in temperate southeastern Australia: Role of the East Australian Current. Estuarine, Coastal and Shelf Science, 72(1), 102-114. https://doi.org/10.1016/j.ecss.2006.10.003
Borstein, S. (2019). dietr: Diet estimated trophic levels. $R$ package version 1.0. Retrieved from github.com/sborstein/dietr

Borstein, S. R., Fordyce, J. A., O'Meara, B. C., Wainwright, P. C., \& McGee, M. D. (2016). Reef fish functional traits evolve fastest at trophic extremes. Nature Ecology \& Evolution, 3(2), 191-199. https://doi. org/10.1038/s41559-018-0725-x

Bradshaw, C. J. A., Brook, B. W., Delean, S., Fordham, D. A., HerrandoPérez, S., Cassey, P., ... Araújo, M. B. (2014). Predictors of contraction and expansion of area of occupancy for British birds. Proceedings of the Royal Society B: Biological Sciences, 281(1786), 20140744. https:// doi.org/10.1098/rspb.2014.0744

Chamberlain, S., \& Szocs, E. (2013). Taxize - Taxonomic search and retrieval in R. F1000Research, 2, 191. Retrieved from http://f1000resea rch.com/articles/2-191/v2

Condie, S. A., Mansbridge, J. V., \& Cahill, M. L. (2011). Contrasting local retention and cross-shore transports of the East Australian Current and the Leeuwin Current and their relative influences on the life histories of small pelagic fishes. Deep Sea Research Part II: Topical Studies in Oceanography, 58(5), 606-615. https://doi.org/10.1016/j.dsr2.2010.06.003

Ehrlich, P. R. (1986). Which animal will invade? In H. A. Mooney \& J. A. Drake (Eds.), Ecology of biological invasions of North America and Hawaii (pp. 79-95). Springer. https://doi.org/10.1007/978-1-4612-4988-7_5

Estrada, A., Morales-Castilla, I., Caplat, P., \& Early, R. (2016). Usefulness of species traits in predicting range shifts. Trends in Ecology \& Evolution, 31(3), 190-203. https://doi.org/10.1016/j.tree.2015.12.014

Feary, D. A., Pratchett, M. S., Emslie, M. J., Fowler, A. M., Figueira, W. F., Luiz, O. J., ... Booth, D. J. (2014). Latitudinal shifts in coral reef fishes: Why some species do and others do not shift. Fish and Fisheries, 15(4), 593-615. https://doi.org/10.1111/faf.12036

Felsenstein, J. (1985). Phylogenies and the comparative method. The American Naturalist, 125(1), 1-15. https://doi.org/10.1086/284325

Figueira, W. F., \& Booth, D. J. (2010). Increasing ocean temperatures allow tropical fishes to survive overwinter in temperate waters. Global Change Biology, 16(2), 506-516. https://doi.org/10.1111/j.1365-2486. 2009.01934.x

Figueira, W. F., Curley, B., \& Booth, D. J. (2019). Can temperature-dependent predation rates regulate range expansion potential of tropical vagrant fishes? Marine Biology, 166(6), 73. https://doi.org/10.1007/ s00227-019-3521-5

Fiske, I., \& Chandler, R. B. (2011). Unmarked: An R package for fitting hierarchical models of wildlife occurrence and abundance. Journal of Statistical Software, 43(10), 1-23.

Foden, W. B., Butchart, S. H. M., Stuart, S. N., Vié, J.-C., Akçakaya, H. R., Angulo, A., ... Mace, G. M. (2013). Identifying the world's most climate change vulnerable species: A systematic trait-based assessment of all birds, amphibians and corals. PLoS ONE, 8(6), e65427. https://doi.org/10.1371/journal.pone.0065427

Fogarty, H. E., Burrows, M. T., Pecl, G. T., Robinson, L. M., \& Poloczanska, E. S. (2017). Are fish outside their usual ranges early indicators of climate-driven range shifts? Global Change Biology, 23(5), 2047-2057. https://doi.org/10.1111/gcb.13635

Fordyce, J. A., Nice, C. C., Hamm, C. A., \& Forister, M. L. (2016) Quantifying diet breadth through ordination of host association. Ecology, 97, 842-849. https://doi.org/10.1890/15-0093

Fowler, A. M., Parkinson, K., \& Booth, D. J. (2017). New poleward observations of 30 tropical reef fishes in temperate southeastern Australia. Marine Biodiversity, 48, 2249-2254. https://doi.org/10.1007/s1252 6-017-0748-6

Froese, R., \& Pauly, D. (2019). Fish base. www.fishbase.org

Gilchrist, G. W. (1995). Specialists and generalists in changing environments. I. Fitness landscapes of thermal sensitivity. The American Naturalist, 146(2), 252-270. https://doi.org/10.1086/285797

Godin, J.-G.- J. (1986). Risk of predation and foraging behaviour in shoaling banded killifish (Fundulus diaphanus). Canadian Journal of Zoology, 64(8), 1675-1678. https://doi.org/10.1139/z86-251 
Hobday, A. J., \& Pecl, G. T. (2014). Identification of global marine hotspots: Sentinels for change and vanguards for adaptation action. Reviews in Fish Biology and Fisheries, 24(2), 415-425. https://doi.org/10.1007/ s11160-013-9326-6

Kingsbury, K. M., Gillanders, B. M., Booth, D. J., \& Nagelkerken, I. (2019). Trophic niche segregation allows range-extending coral reef fishes to co-exist with temperate species under climate change. Global Change Biology, 26, 721-733. https://doi.org/10.1111/gcb.14898

La Sorte, F. A., \& Jetz, W. (2012). Tracking of climatic niche boundaries under recent climate change. Journal of Animal Ecology, 81(4), 914925. https://doi.org/10.1111/j.1365-2656.2012.01958.x

Lodge, D. M. (1993). Biological invasions: Lessons for ecology. Trends in Ecology \& Evolution, 8(4), 133-137. https://doi.org/10.1016/01695347(93)90025-K

Matis, P. A., Donelson, J. M., Bush, S., Fox, R. J., \& Booth, D. J. (2018). Temperature influences habitat preference of coral reef fishes: Will generalists become more specialised in a warming ocean? Global Change Biology, 24(7), 3158-3169. https://doi.org/10.1111/gcb.14166

McKnight, E., García-Berthou, E., Srean, P., \& Rius, M. (2017). Global meta-analysis of native and nonindigenous trophic traits in aquatic ecosystems. Global Change Biology, 23(5), 1861-1870. https://doi. org/10.1111/gcb.13524

McLean, M., Mouillot, D., \& Auber, A. (2018). Ecological and life history traits explain a climate-induced shift in a temperate marine fish community. Marine Ecology Progress Series, 606, 175-186. https://doi. org $/ 10.3354 /$ meps12766

Monaco, C. J., \& Helmuth, B. (2011). Tipping points, thresholds and the keystone role of physiology in marine climate change research. Advances in Marine Biology, 60, 124-154.

Parmesan, C., \& Yohe, G. (2003). A globally coherent fingerprint of climate change impacts across natural systems. Nature, 421(6918), 37-42.

Pearce, A., Hutchins, B., Hoschke, A., \& Fearns, P. (2016). Record high damselfish recruitment at Rottnest Island, Western Australia, and the potential for climate-induced range extension. Regional Studies in Marine Science, 8, 77-88. https://doi.org/10.1016/j.rsma.2016.09.009

Pecl, G. T., Araújo, M. B., Bell, J. D., Blanchard, J., Bonebrake, T. C., Chen, I.-C., ... Williams, S. E. (2017). Biodiversity redistribution under climate change: Impacts on ecosystems and human well-being. Science, 355(6332), https://doi.org/10.1126/science.aai9214

Perry, A. L., Low, P. J., Ellis, J. R., \& Reynolds, J. D. (2005). Climate change and distribution shifts in marine fishes. Science, 308(5730), 19121915. https://doi.org/10.1126/science.1111322

Pinsky, M. L., Eikeset, A. M., McCauley, D. J., Payne, J. L., \& Sunday, J. M. (2019). Greater vulnerability to warming of marine versus terrestrial ectotherms. Nature, 569(7754), 108-111. https://doi.org/10.1038/ s41586-019-1132-4

Pinsky, M. L., Worm, B., Fogarty, M. J., Sarmiento, J. L., \& Levin, S. A. (2013). Marine taxa track local climate velocities. Science, 341(6151), 1239-1242. https://doi.org/10.1126/science.1239352

Poloczanska, E. S., Babcock, R. C., Butler, A., Hoegh-Guldberg, O., Kunz, T., Matear, R., ... Richardson, A. J. (2007). Climate change and Australian marine life. In R. Gibson, R. Atkinson, \& J. Gordon (Eds.), Oceanography and marine biology (Vol. 20074975, pp. 407-478). CRC Press. https://doi.org/10.1201/9781420050943.ch8

Poloczanska, E. S., Brown, C. J., Sydeman, W. J., Kiessling, W., Schoeman, D. S., Moore, P. J., ... Richardson, A. J. (2013). Global imprint of climate change on marine life. Nature Climate Change, 3(10), 919-925. https://doi.org/10.1038/nclimate1958

Pratchett, M. S., Berumen, M. L., Marnane, M. J., Eagle, J. V., \& Pratchett, D. J. (2008). Habitat associations of juvenile versus adult butterflyfishes. Coral Reefs, 27(3), 541-551. https://doi.org/10.1007/s0033 8-008-0357-8

Ridgway, K. R. (2007). Long-term trend and decadal variability of the southward penetration of the East Australian Current. Geophysical Research Letters, 34(13), https://doi.org/10.1029/2007GL030393
Riechert, S. E. (1991). Prey abundance vs diet breadth in a spider test system. Evolutionary Ecology, 5(3), 327-338. https://doi.org/10.1007/ BF02214236

Rooney, N., McCann, K. S., \& Moore, J. C. (2008). A landscape theory for food web architecture. Ecology Letters, 11(8), 867-881. https://doi. org/10.1111/j.1461-0248.2008.01193.x

Roy, K., Jablonski, D., \& Valentine, J. W. (2002). Body size and invasion success in marine bivalves. Ecology Letters, 5(2), 163-167. https://doi. org/10.1046/j.1461-0248.2002.00316.x

Schoener, T. W. (1974). Resource partitioning in ecological communities. Science, 185(4145), 27-39. https://doi.org/10.1126/science.185.4145.27

Siegel, D. A., Mitarai, S., Costello, C. J., Gaines, S. D., Kendall, B. E., Warner, R. R., \& Winters, K. B. (2008). The stochastic nature of larval connectivity among nearshore marine populations. Proceedings of the National Academy of Sciences of the United States of America, 105(26), 8974-8979. https://doi.org/10.1073/pnas.0802544105

Smith, S. M., Fox, R. J., Booth, D. J., \& Donelson, J. M. (2018). 'Stick with your own kind, or hang with the locals?' Implications of shoaling strategy for tropical reef fish on a range-expansion frontline. Global Change Biology, 24(4), 1663-1672. https://doi.org/10.1111/gcb.14016

Stasinopoulos, D. M., \& Rigby, R. A. (2007). Generalized additive models for location scale and shape (GAMLSS) in R. Journal of Statistical Software, 023(i07). Retrieved from https://EconPapers.repec.org/ RePEc:jss:jstsof:v:023:i07

Sunday, J. M., Bates, A. E., \& Dulvy, N. K. (2012). Thermal tolerance and the global redistribution of animals. Nature Climate Change, 2(9), 686-690. https://doi.org/10.1038/nclimate1539

Sunday, J. M., Pecl, G. T., Frusher, S., Hobday, A. J., Hill, N., Holbrook, N. J., ... Worm, B. (2015). Species traits and climate velocity explain geographic range shifts in an ocean-warming hotspot. Ecology Letters, 18(9), 944-953. https://doi.org/10.1111/ele.12474

Tingley, M. W., Monahan, W. B., Beissinger, S. R., \& Moritz, C. (2009). Birds track their Grinnellian niche through a century of climate change. Proceedings of the National Academy of Sciences of the United States of America, 106(Suppl 2), 19637-19643. https://doi. org/10.1073/pnas.0901562106

van Buuren, S., \& Fredriks, M. (2001). Worm plot: A simple diagnostic device for modelling growth reference curves. Statistics in Medicine, 20(8), 1259-1277. https://doi.org/10.1002/sim.746

Wilson, S. K., Depcyznski, M., Fisher, R., Holmes, T. H., Noble, M. M., Radford, B. T., ... Fulton, C. J. (2018). Climatic forcing and larval dispersal capabilities shape the replenishment of fishes and their habitat-forming biota on a tropical coral reef. Ecology and Evolution, 8(3), 1918-1928. https://doi.org/10.1002/ece3.3779

Wong-Ala, J. A. T. K., Comfort, C. M., Gove, J. M., Hixon, M. A., McManus, M. A., Powell, B. S., ... Neuheimer, A. B. (2018). How life history characteristics and environmental forcing shape settlement success of coral reef fishes. Frontiers in Marine Science, 5, 65. https://doi. org/10.3389/fmars.2018.00065

\section{SUPPORTING INFORMATION}

Additional supporting information may be found online in the Supporting Information section.

How to cite this article: Monaco CJ, Bradshaw CJA, Booth DJ, Gillanders BM, Schoeman DS, Nagelkerken I. Dietary generalism accelerates arrival and persistence of coral-reef fishes in their novel ranges under climate change. Glob Change Biol. 2020;26:5564-5573. https://doi.org/10.1111/gcb.15221 